\title{
The association of pregnancy and leprosy-III. Erythema nodosum leprosum in pregnancy and lactation
}

\author{
M ELIZABETH DUNCAN* \& J M H PEARSON† \\ Medical Research Council Leprosy Project, Addis Ababa, Ethiopia
}

Accepted for publication 11 October 1983

\begin{abstract}
Summary Seventy-six women with lepromatous leprosy were studied during 79 pregnancies and followed up during lactation for up to 24 months. Ten out of 45 BL patients $(22 \%)$ and 20 out of $34 \mathrm{LL}$ patients $(59 \%)$ developed erythema nodosum leprosum (ENL) during the course of the study. Only 4 out of 30 patients were BI negative, although the duration of effective treatment for leprosy ranged from 1 to 14 years. Thirteen of the $30 \mathrm{ENL}$ patients were suspected of developing dapsone resistance during the study period. The incidence of ENL was highest in the first trimestre with a second peak in the third trimestre, coinciding with the peak of relapse. Fifteen per cent of the women suffered from ENL almost continuously from the third trimestre to 15 months postpartum. In pregnancy ENL was seen more frequently in skin than in nerve or other tissue; however, after delivery, particularly in the recurrent or persistent episodes, ENL was seen more commonly in nerve than in skin. Significant sensory and/or motor loss occurred in 30 out of 38 episodes of ENL nerve involvement. The significance of these findings is discussed.
\end{abstract}

\section{Introduction}

Erythema nodosum leprosum (ENL) has been considered to be a form of immune complex disease characterized by the deposition of immunoglobulin and complement in the vicinity of Mycobacterium leprae antigen. ${ }^{1-3}$ Tissues affected in decreasing order of frequency are skin, nerve, lymphnodes, joints and other sites. ${ }^{4}$ Immune complexes have been detected by the precipitation of $\mathrm{C}_{\mathrm{lq}}$ in a high percentage of sera from patients with ENL. ${ }^{5}$ However, the actual role of immune complexes in the immunopathology of ENL remains to be elucidated. ${ }^{5,6}$ Recently it has been suggested that depletion of suppressor T-cells may be responsible for the initiation of ENL. ${ }^{7}$

Present addresses:

* Al Qassim Hospitalk, PO Box 3500, Sharjah, UAE.

$\dagger$ Dhoolpet Leprosy Research Centre, Karwan, Hyderabad 500 006, A P, India. 
ENL is seen chiefly in patients with lepromatous $\left(L_{\mathrm{p}} \text { or } \mathrm{LL}_{\mathrm{s}}\right)^{8}$ leprosy, where more than $50 \%$ of patients may experience ENL during the first year of treatment. ${ }^{9}$ It occurs less frequently in patients with borderline lepromatous (BL) leprosy.

Factors which increase the levels of antigen, antibody or complement could well affect or precipitate ENL. A number of such factors are associated with pregnancy:

(a) During the first trimestre of pregnancy there is inversion of the T-cell: B-cell ratio due to physiological depletion of suppressor T-cells; ${ }^{10}$ this might be related to the development of ENL at this time. (b) The increased level of circulating immune complexes (not specifically anti-mycobacterial) in late pregnancy ${ }^{11,} 12$ may encourage the appearance of ENL at that time. (c) Pregnancy in leprosy is often associated with relapse in 'cured' patients, and with a tendency to increased activity in patients under treatment, accompanied by a shift towards the lepromatous end of the leprosy spectrum. ${ }^{12,}{ }^{13}$ All these are likely to be associated with an increase in levels of mycobacterial antigen; such an increase has been demonstrated even in patients relapsing with tuberculoid (BT) leprosy. ${ }^{14}$

It is hardly surprising that pregnancy has been suggested as a precipitating factor of $\mathrm{ENL}^{15}$ and, indeed, recorded as such in retrospective studies. ${ }^{16},{ }^{17}$ This paper reports the association of ENL with pregnancy and lactation as observed in a prospective study carried out by the Medical Research Council Leprosy Project in Addis Ababa, Ethiopia, during 1975-78.

\section{Patients and methods}

\section{CLASSIFICATION AND TREATMENT OF PATIENTS}

Seventy-six women with lepromatous leprosy were studied during 79 pregnancies and followed up during lactation. The classification according to Ridley \& Jopling ${ }^{18}$ was:

Borderline lepromatous leprosy (BL) - 44 women (45 pregnancies).

Lepromatous leprosy ( $L_{\mathrm{p}}$ and $\left.\mathrm{LL}_{\mathrm{s}}\right)$ - 32 women (34 pregnancies).

Sixty-five of the women (67 pregnancies) were receiving dapsone $100 \mathrm{mg}$ daily, 4 under trial conditions ${ }^{19}$ for suspected low-grade dapsone resistance; 6 women had dapsone-resistant leprosy and were receiving clofazimine $300 \mathrm{mg}$ weekly (4 LL, 5 pregnancies) or triple therapy with dapsone, thiambutosine and rifampicin (2 $\mathrm{BL})$. Five patients at the start of the study were not receiving any anti-leprosy treatment: 1 'cured' BL had been released from control (RFC) after 20 years of treatment; 3 initially classified as 'cured' borderline tuberculoid (BT/RFC) all relapsed with active BL leprosy during the third trimestre; 1 healthy control 
developed overt leprosy during the first 3 months of lactation. The 'healthy control' new case, and 2 of the $3 \mathrm{BT} / \mathrm{RFC}$ patients were started on treatment with dapsone $100 \mathrm{mg}$ daily as soon as active leprosy was diagnosed; the third BT/RFC failed to attend for follow-up and was untraceable after delivery.

\section{SELECTION AND ASSESSMENT OF PATIENTS}

Selection of patients was based chiefly on the patients' willingness to participate in the study. Assessment of the women's leprosy status was made on entry to the study, during pregnancy at 3-month intervals whenever possible, and after delivery at 6-monthly intervals. Full examination included inspection and palpation of the skin, peripheral nerves and regional lymphnodes, clinical drawings, skin smears and biopsies, sensory skin testing (SST) and voluntary muscle testing (VMT); nerve conduction velocity (EMG) was measured in selected patients where it was difficult to assess whether nerve damage was of old standing or recent origin. In the presence of obvious clinical changes (such as facial paralysis or 'tic' of the facial muscles; wasting of the intrinsic muscles of the hand; 'curving' of the fourth and fifth fingers; claw hand or foot drop), formal VMT's were sometimes omitted. Similarly, in a few patients with extensive anaesthesia with anhidrosis, formal SST's were omitted. These are reported as 'clinical assessments' (Table 1). Details regarding the patient's history and

Table 1. Severity of nerve damage during each episode of neuritis

\begin{tabular}{|c|c|c|c|c|c|c|c|}
\hline & & \multicolumn{4}{|c|}{ Degree of nerve damage } & \multirow[b]{3}{*}{ Total } & \multirow{3}{*}{$\begin{array}{c}\text { No nerve damage } \\
\text { detected } \\
\text { (episodes) }\end{array}$} \\
\hline & & & tor* & Sen & soryt & & \\
\hline \multicolumn{2}{|c|}{ Type of neuritis } & Mild & Severe & Mild & Severe & & \\
\hline \multirow[t]{2}{*}{ Overt } & One nerve only & 1 & 1 & 0 & 0 & 2 & \multirow{2}{*}{8} \\
\hline & Many nerves & 7 & 5 & 5 & 4 & 21 & \\
\hline \multirow[t]{2}{*}{ Silent } & One nerve only & 1 & 1 & 2 & 1 & 5 & \\
\hline & Many nerves & 2 & 6 & 3 & 4 & 15 & \\
\hline Total & & 11 & 13 & 10 & 9 & 43 & 8 \\
\hline
\end{tabular}

* Mild damage: loss of one or two VMT grades in one or more nerves, or EMG evidence only.

Severe damage: loss of three or more VMT grades in one or more nerves, or clinical assessment only.

$\dagger$ Mild damage: loss of one or two sensory test areas in one or more nerves. Severe damage: loss of three or more sensory test areas in one or more nerves, or clinical assessment only. 
leprosy status prior to entry to the study were obtained from the hospital records. Full details are recorded in an earlier publication. ${ }^{13}$

\section{INCREASED ACTIVITY OF LEPROSY ('RELAPSE')}

Relapse was considered to have occurred where there was conversion of negative to positive BI or MI, where biopsy showed histological features of relapse with presence of acid-fast bacilli, solid staining, or where there were new nodules or skin infiltration not caused by reaction (histological diagnosis). Thirteen out of 21 had all 3 criteria, 2 had 2 criteria, 2 showed relapse on biopsy only, 1 showed conversion of negative to positive $\mathrm{MI}$ with rising $\mathrm{BI}$, and 3 showed increase of BI only as a transient phenomenon during the third trimestre. ${ }^{13}$ Patients continued to take dapsone throughout pregnancy; relapse was therefore considered likely to be caused by the emergence of dapsone-resistant leprosy. ${ }^{19}$

\section{NEURITIS IN PREGNANCY AND LACTATION}

We have used the term 'overt neuritis' for the accepted definition of neuritis as tender nerves with/without objective evidence of motor or sensory loss. ${ }^{20}$ 'Silent neuritis' has been defined as loss of motor or sensory function without clinical evidence of nerve tenderness. ${ }^{21}$ In both overt and silent neuritis there may be new nerve enlargement. When silent neuritis occurred in a lepromatous patient (BL or LL) who had ENL either at the same time or previously, we have regarded the silent neuritis as being due to ENL.

\section{Results}

Patients were admitted to the study over a 12-month period and followed up for varying lengths of time up to 24 months postpartum; the 3 months prior to pregnancy provided a baseline for the prevalence of complications of leprosy in women of child-bearing age. The incidence of ENL and increased activity of leprosy (relapse) are expressed as a percentage of the total number of women in the study in any 3-month period.

Thirty out of 79 patients $(38 \%$ ) developed ENL during the course of the study: 10 out of $45 \mathrm{BL}$ patients $(22 \%)$ and 20 out of $34 \mathrm{LL}$ patients $(59 \%)$. Twenty-nine of these patients had clinically diagnosable ENL in the skin on one or more occasions; the thirtieth, originally $\mathrm{BT} / \mathrm{RFC}$, developed iridocyclitis.

OCCURRENCE OF ENL IN ASSOCIATION WITH DURATION OF TREATMENT (FIGURE 1)

Fourteen patients $(47 \%)$ had ENL within 4 years of the start of effective treatment 


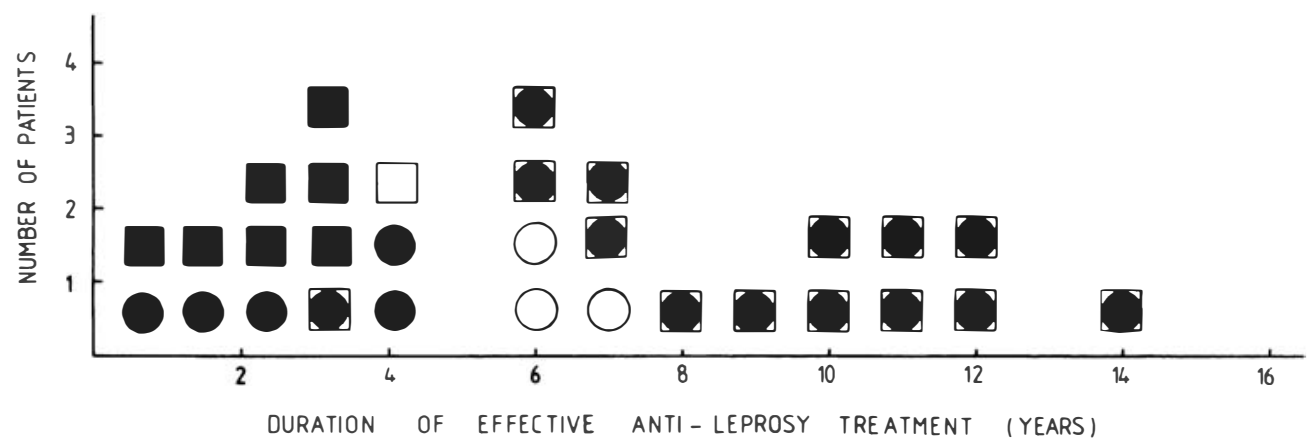

\begin{tabular}{|c|c|c|c|c|}
\hline B. I. + ve & ON & & I ve & DAPSONE \\
\hline B I. - ve & DAPSONE & & - ve & RESISTANT \\
\hline BI +ve & $\begin{array}{l}\text { RELAPSE / SUSPECTED } \\
\text { DURING STUDY }\end{array}$ & DAPSONE & RESI & \\
\hline
\end{tabular}

Figure 1. Duration of effective anti-leprosy therapy in 30 patients who developed ENL in association with pregnancy and lactation.

for leprosy, either initial treatment with dapsone, or dapsone under trial conditions ( 3 out of 4 patients already having evidence of suspected dapsoneresistant leprosy),${ }^{19}$ or alternative therapy in the case of 4 out of 6 dapsone-resistant patients ( 5 out of 7 pregnancies). All but one of these were BI positive. The remaining 16 patients showed ENL after 6-14 years of treatment with dapsone. Only 3 were BI negative. Two patients who had been on treatment for 11 years and were BI positive, had had 2-3 years of additional treatment with clofazimine for persistent ENL. Thirteen of the 30 patients were suspected of developing dapsone resistance during the study period.

\section{TIMING OF FIRST EPISODES OF ENL DURING THE STUDY}

The periods during which patients developed their first episodes of ENL during the study are shown in Figure 2(b). The incidence was highest during the first trimestre with a fall in the second, then a rise in the third, coinciding with the peak of relapse. There was a steady decline during lactation, only 2 cases starting after 9 months. However, when all patients suffering from ENL during a period are recorded (Figure 2(c)), it can be seen that a high proportion of patients with ENL have it persistently for many months after delivery; indeed, $15 \%$ of the group studied suffered from ENL or neuritis for the 18-month period from the third trimestre to 15 months postpartum. While the highest incidence of onset of ENL was during the first trimestre, before the women had realized they were pregnant and thus were attending the hospital clinics rather than the special clinics for this study, it is unlikely that ENL was either under-diagnosed or over-diagnosed: 


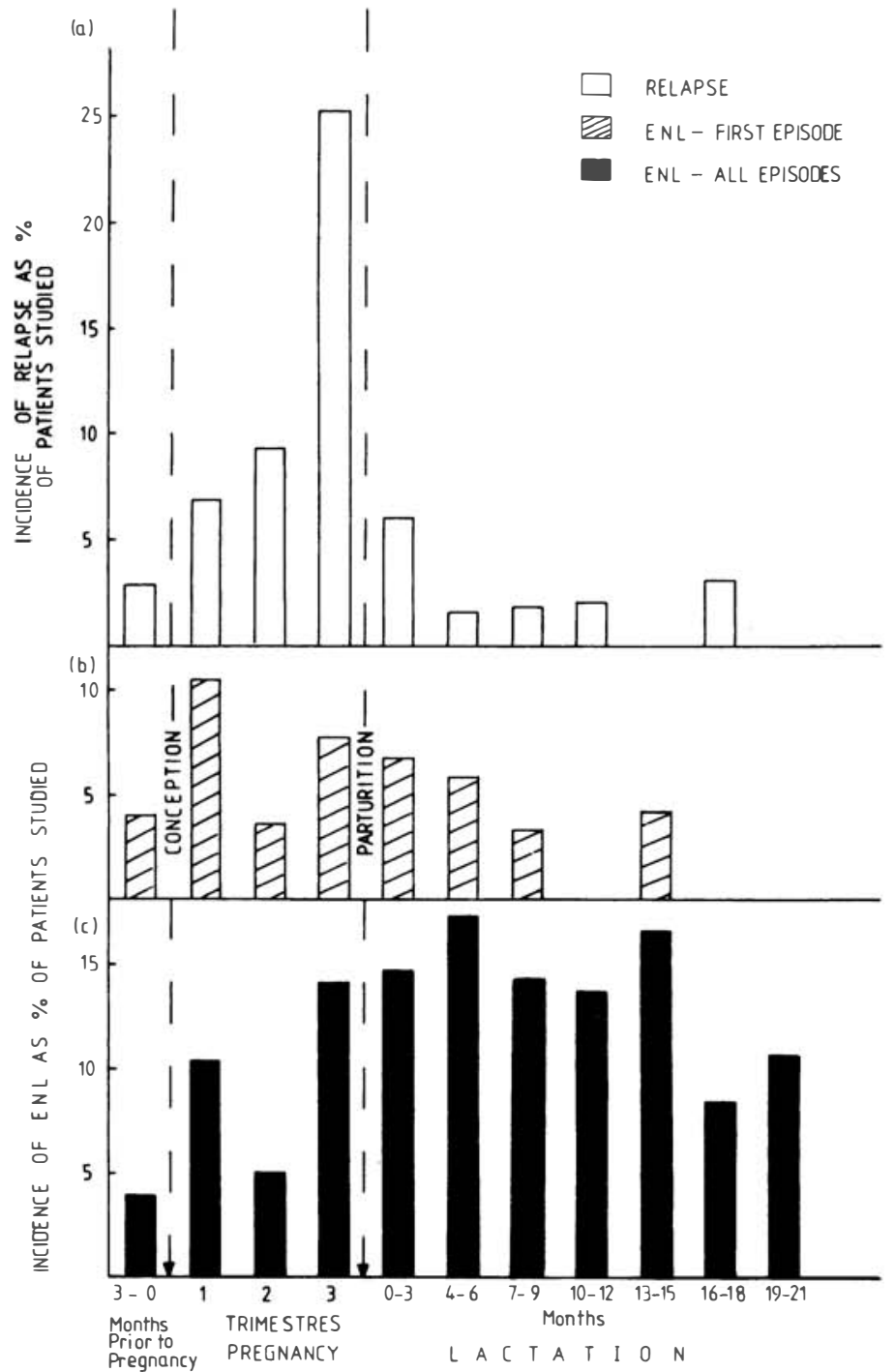

Figure 2. Percentage of patients: (a) showing evidence of relapse; (b) developing ENL (first episode); (c) suffering from ENL (all episodes) during each trimestre of the study period.

most patients with troublesome ENL attended hospital specifically on that account and the hospital doctors who saw them were leprologists of repute. Only 6 of the women suffered from persistent ENL lasting for 6 months or more: a larger proportion suffered from recurrent episodes of ENL.

ENL AND TISSUES INVOLVED, ACCORDING TO PREGNANCY AND LACTATION

During the 3 months prior to pregnancy, ENL was recorded only in the skin. 
Throughout pregnancy ENL was seen more in the skin than in nerve or other tissue; however, after delivery, particularly in the recurrent or persistent episodes, ENL was seen more commonly in nerve than in skin (Figure 3). This was especially the case after the ninth month of lactation. Four patients ( 6 episodes) had evidence of ENL occurring in tissues other than skin or nerve; 2 episodes involved the eye, 2 episodes involved bone - both women had very tender tibiae and dactylitis, 2 had arthritis with concomitant nerve and/or skin ENL. All 4 women had ENL in association with relapse. Three other women had gross peripheral oedema in association with skin ENL. Six women had ENL in association with upgrading (5) or reversal reaction in skin (1) confirmed histologically.

ENL AND CLINICAL FEATURES OF LEPROSY DURING PREGNANCY AND LACTATION

Symptoms and clinical features of mothers who had ENL are shown in Table 2. Table 3 shows the symptoms and clinical features of mothers who did not have ENL.

The total duration of treatment in the patients who had ENL was rather longer than in those who did not have ENL: the period of effective treatment, however, was shorter, due to the inclusion of patients who had already developed dapsone resistance. All clinical features, except reversal reaction in BL patients,

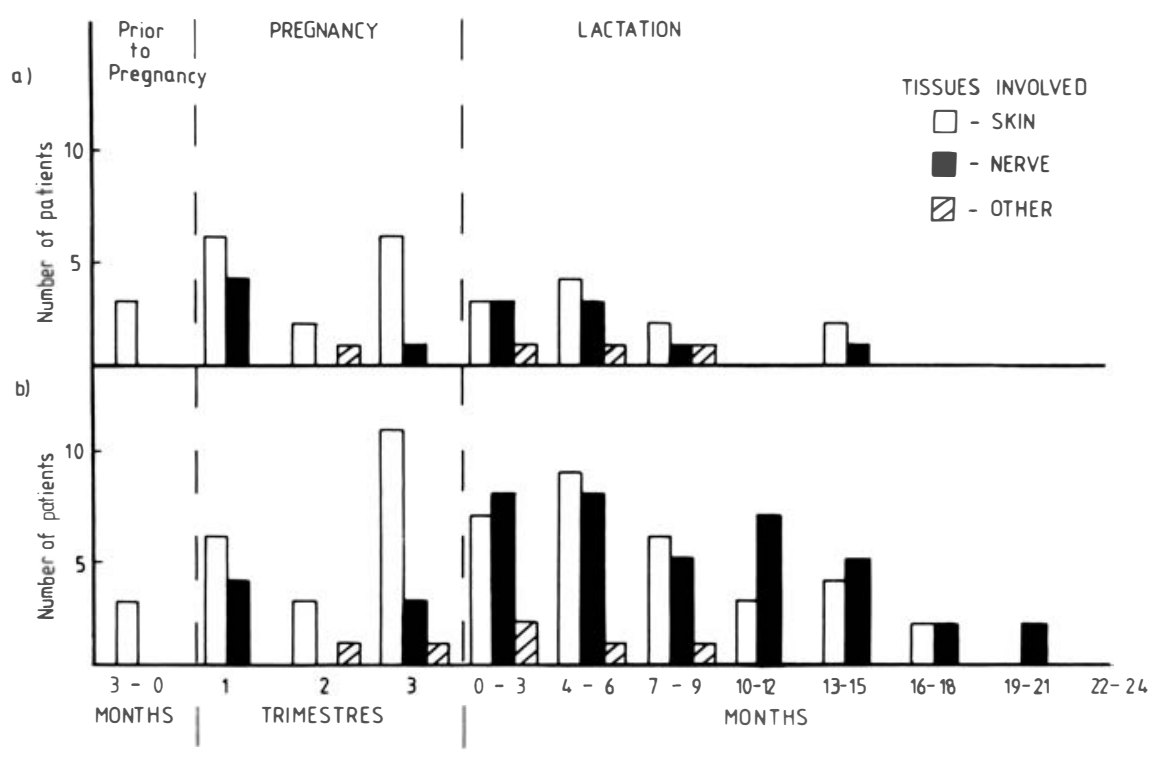

Figure 3. ENL in pregnancy and lactation showing the tissues involved: (a) during the first episode; (b) during all episodes, single, recurrent and persistent. (NB: In any single episode, one, two or more tissues may be involved.) 


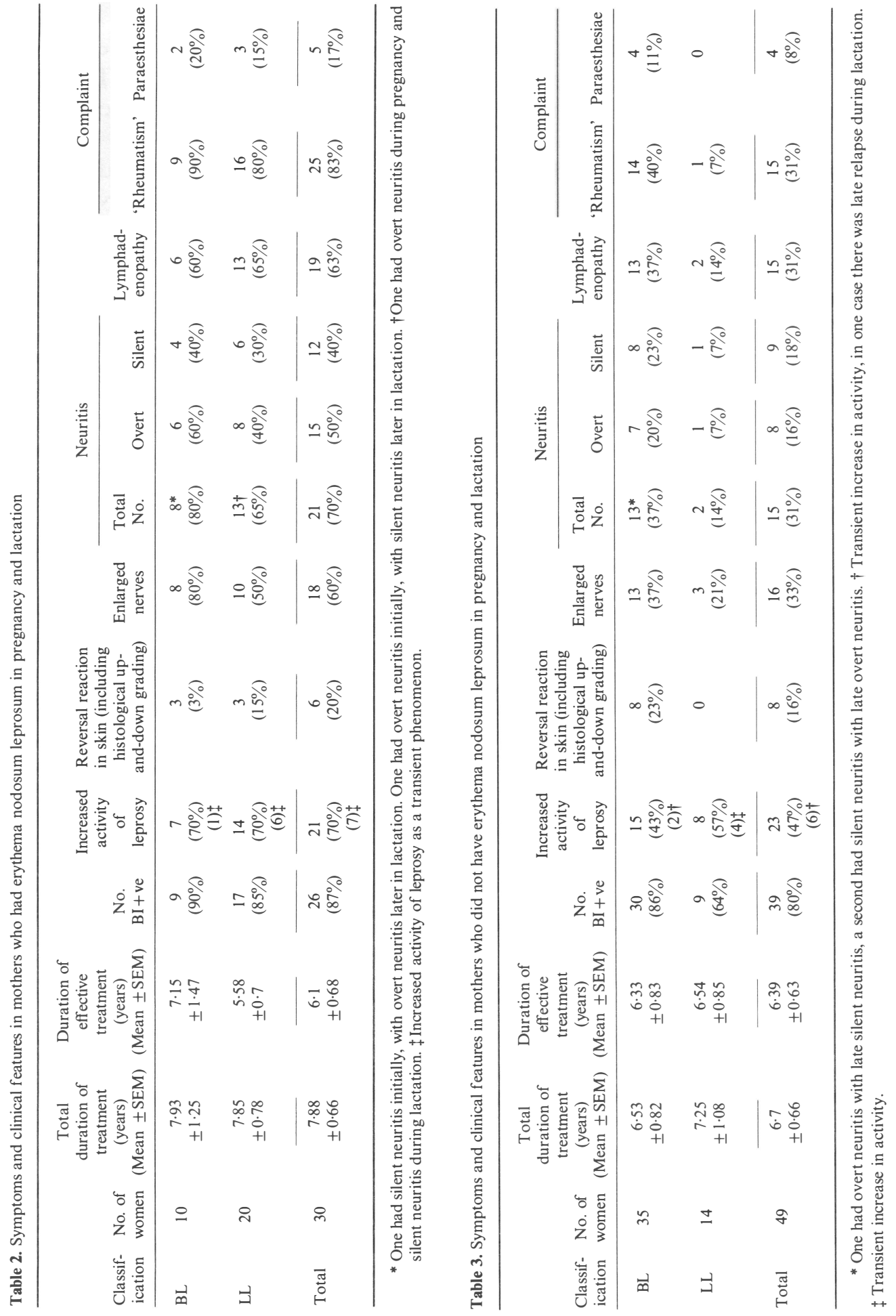


were more commonly seen in patients who also had ENL than those who did not have ENL, especially in the LL patients. Thus there appears to be a correlation between ENL, relapse, new nerve enlargement, neuritis and lymphadenopathy. The complaint of 'rheumatism' was heard from $90 \%$ of BL patients with ENL and $80 \%$ of LL patients with ENL. Paraesthesiae, 'burning sensation in the skin', was a complaint of pregnancy while 'rheumatism' tended to be a complaint of lactation. In the BL group, enlarged nerves, neuritis and lymphadenopathy were also associated with reversal reaction during lactation and followed relapse in late pregnancy.

\section{ENL AND NEURITIS IN PREGNANCY AND LACTATION}

The extent of nerve involvement in ENL in pregnancy and lactation has been shown in Figure 3. The degree of nerve damage is shown in Table 1. Six patients had 8 episodes of ENL nerve involvement with acutely tender peripheral nerves in which no motor or sensory loss was demonstrated. However, there were 30 episodes in which significant motor and/or sensory loss occurred. There was only one episode in which there was loss of function of a single nerve; however, the patient developed multi-nerve involvement during the next episode of neuritis.

We observed that many nerves were involved in each episode of neuritis. Usually in overt neuritis twice the number of nerves were recorded as showing tender nerve enlargement, as showed loss of function. This may reflect the fact that the methods of sensory testing were designed to demonstrate loss or recovery of protective sensation rather than absolute loss of sensation. Severe motor nerve damage was recorded in 13 episodes of neuritis and severe sensory nerve damage was recorded in 9 episodes of neuritis.

A further measurement of the severity of the neuritis is seen in the number of patients who required treatment with prednisolone for nerve damage for periods of up to several months. Six out of $8 \mathrm{BL}$ patients and 10 out of $13 \mathrm{LL}$ patients received prednisolone; 5 out of 16 patients receiving prednisolone and 1 of the 5 without prednisolone showed improvement in nerve function at the time of the last assessment.

\section{ENL AND INFECTIONS SEEN DURING PREGNANCY AND LACTATION}

Two patients, both LL, deserve special comment.

(i) S.M. A9/256, a secundigravida who had been treated with dapsone $100 \mathrm{mg}$ daily for 3 years, was referred to the hospital during the second trimestre from an outlying clinic for severe ENL which had started during the first trimestre. During the first 6 months of pregnancy, she had severe ENL in the skin which required treatment with prednisolone $20-30 \mathrm{mg}$ daily. In the third trimestre, she had a transient rise in BI, skin ENL persisted, and in addition she developed neuritis and arthritis with acutely tender swollen knees and hands. After delivery, the 
ENL stopped suddenly, but restarted as abruptly 21 days postpartum, with skin, nerve and bone involvement, acutely tender tibiae and dactylitis. Chest X-ray showed pulmonary tuberculosis. She improved on treatment with anti-tuberculous drugs, and clofazimine for ENL and was discharged home for further treatment by her home clinic.

(ii) Y.T. A9/64, a gravida 4 who had received dapsone monotherapy for 9 years, had no problems during her pregnancy. At 6 months postpartum she was acutely ill with endemic typhus and required in-patient treatment for 3 weeks. During the first week of the febrile illness she had developed skin ENL. This became very troublesome and after 2 months ENL involved nerves and bone as well. Like S.M., she had acutely tender tibiae and dactylitis. At this time biopsy showed ENL in the skin and short solid AFB in deep muscle, indicating incipient relapse. She developed new nerve damage with motor and sensory loss. Despite treatment with prednisolone $20-30 \mathrm{mg}$ daily, she had persistent sensory loss at her last assessment.

\section{Discussion}

It has been generally accepted that lepromatous patients who develop ENL do so within the first 2 years of treatment. An overall rate of approximately $40 \%$ has been recorded, of which $90 \%$ of $L L\left(L L_{p}\right), 62 \%$ of $L I\left(L L_{s}\right)$ and $32 \%$ of BL patients suffer from the reaction within $2 \frac{1}{2}$ years of starting treatment. ${ }^{9}$ It has been suggested that late ENL may be the first indication of the development of dapsone resistance, but studies in Ethiopia failed to confirm this. ${ }^{22}$ Release of antigen during initial therapy, together with immunoglobulin and complement has been thought to form the immune complexes which have been considered as causative of most cases of ENL. ${ }^{1-3}$ Pregnancy has been reported as precipitating ENL and relapse without comment on mechanism. ${ }^{15-17,23,24}$

During normal pregnancy there is an increase in the number of antibodyantigen complexes, particularly towards the end of pregnancy, ${ }^{11}, 12,25$ but the implications of this observation remain obscure. In studying patients with leprosy, it is tempting to link this general observation with the increased incidence of ENL observed in our study and assume a cause-and-effect association. However, this would not explain the initial peak of ENL in the first trimestre. During the first trimestre of pregnancy there is inversion of the T-cell: B-cell ratio due to physiological depletion of suppressor T-cells. ${ }^{10}$ The hypothesis that the initial phase of ENL is due to imbalance of T-cell subsets with decrease in the population of suppressor T-cells ${ }^{7}$ presents an interesting alternative which might well account for the upsurge of ENL seen in the first trimestre. Further evidence for the implication of disturbed T-cell function in the pathogenesis of ENL may be seen in the 'clinically puzzling mixtures of type 1 and type 2 reaction' observed in some of our patients associated with relapse. ${ }^{21}$

In 11 out of 21 cases, ENL preceded or accompanied the first sign of relapse. 
Mouse foot-pad tests were undertaken in 7 of the 21 patients and all showed low-grade dapsone resistance. ${ }^{19}$ This may indicate either that the patients had been taking their (self-administered) treatment irregularly: urine tests for dapsone were not performed to study the question; or that pregnancy immunosuppression is a factor in the stepwise development of dapsone resistance. It seems possible that in pregnancy, where there is a state of immunological instability, ENL is a significant symptom in, or sign of, the development of dapsone resistance.

Probably the most important observation in this study is the association between ENL and severe nerve damage. It is sometimes stated that although ENL can occur in nerves, causing severe nerve tenderness, major nerve damage does not usually occur. For this reason, treatment with corticosteroids is frequently eschewed and most patients are treated symptomatically. While this may be true of non-pregnant patients, the same cannot be said of women during pregnancy or lactation. We have already recorded an increased prevalence of neuritis in association with pregnancy and lactation. ${ }^{21}$ It may be that with alterations of CMI during pregnancy and lactation, nerves previously considered as privileged sites for $M$. leprae become especially vulnerable.

The observation that ENL is more common in the skin during pregnancy and more common in nerve during lactation may be of interest in reappraising the pathogenesis of ENL. A similar observation has been made regarding the timing of reversal reaction in association with pregnancy and lactation. ${ }^{26}$ It is tempting to suggest that, as in reversal reaction where surface antigens of $M$. leprae play a part in skin reactions while cytoplasmic antigens are responsible for reactions in nerve, ${ }^{27}$ in ENL skin reaction occurs during the period of relapse when surface antigens are predominant and nerve reaction is seen as cytoplasmic antigens are exposed. Or, if, as has been suggested, CMI plays a part in the pathogenesis of ENL, a further explanation for the occurrence of ENL in the skin during pregnancy and in nerve during lactation could be as follows. During pregnancy, due to suppression of CMI, immune responses are weaker, hence antigen in nerves is less accessible and remains 'hidden' until postpartum when reactions are observed in nerve. Reaction in skin, due to the antigen being more accessible, can occur during pregnancy even though the immune response is diminished (D S Ridley, personal communication).

Evaluation of lymphocyte transformation (LTT) in pregnant women who were classified as cured tuberculoid (BT/RFC) increased our understanding of some of the hitherto 'bizarre' results observed in some women with borderline leprosy in reversal reaction ( $G$ Bjune, personal communication). In similar fashion, a prospective study of a few well-controlled lepromatous patients $\left(L L_{p}\right.$, $\mathrm{LL}_{\mathrm{s}}$ and $\mathrm{BL}$ ) with ENL in early pregnancy-including measurement of total white celi count, T- and B-cells and lymphocyte transformation-might throw light on the pathogenesis of ENL in terms of T- and B-cell function and response to surface or cytoplasmic $M$. leprae antigen. 
We have observed during the course of the study the coincidence of ENL and reversal reaction in patients who relapsed during late pregnancy and the puerperium. It is possible that some of the cases of late silent neuritis seen in lepromatous patients with ENL were actually due to reversal reaction rather than to ENL. A further study with serial nerve biopsies during pregnancy and lactation would be necessary to provide factual information on this point.

The role of infections other than leprosy in triggering off ENL is seen in two patients reported in detail. Persistent ENL has been associated with underlying tuberculosis (Pearson, unpublished observations), only remitting after treatment for tuberculosis was established. As both tuberculosis and endemic typhus are controlled to a variable extent by cell-mediated immunity, it is possible that T-cell suppression associated with those infections causes ENL, thus providing further supportive evidence for Mshana's hypothesis.

The significance of ENL in association with pregnancy and lactation is: (i) first occurrence in early pregnancy when the woman may not even realize that she is pregnant, especially if she is still lactating after her previous pregnancy; (ii) significant morbidity during pregnancy and lactation, possibly necessitating hospital treatment as an in-patient; (iii) association with relapse/dapsone resistance; (iv) a potential cause of permanent nerve damage; and (v) necessity for additional drug therapy.

In ideal circumstances, unexplained ENL occurring in a woman treated with anti-leprosy drugs for more than 4 years should alert the leprologist to carry out a urinary pregnancy test, a urinary examination for levels of dapsone, initial assessment for early dapsone resistance, and assessment of motor and sensory nerve function.

All drugs given during the first trimestre of pregnancy carry the risk of harming the foetus. Because of the teratotoxicity of thalidomide, it is absolutely contra-indicated in all women of child-bearing age. Prednisolone given during the first trimestre carries a slight risk of causing cleft palate. We have suggested that the best drug currently available would be clofazimine which, given from the second trimestre onwards for a period of approximately 1 year, would: (a) deal with the problems of transient relapse; and (b) prevent or treat ENL. ${ }^{19}$

However, clofazimine has not been used extensively during pregnancy and all cases so treated should be carefully documented and reported. In rat pregnancy, clofazimine has been shown to cause abortion, ${ }^{28}$ and in human pregnancy there is suggestive evidence that clofazimine suppresses the placental production of oestriol, although the significance of this is not clear. ${ }^{29}$

\section{Acknowledgments}

We are most grateful to the staff and patients of the Addis Ababa Leprosy Hospital for their cooperation in this study; Miss Jean Watson, Mr Wim 
Brandsma and the staff of the Physiotherapy Department for carrying out the sensory skin testing and voluntary muscle testing; and Dr B Naafs for measuring nerve conduction velocity in selected patients. We also thank Dr D S Ridley who provided independent histological classification of the patients in the study and who read the serial biopsies of patients in reaction.

\section{References}

1 Wemambu SNC, Turk JL, Waters MFR, Rees RJW. Erythema nodosum leprosum: A clinical manifestation of the Arthus phenomenon. Lancet, 1969; ii: 933-5.

2 Waters MFR, Turk JL, Wemambu SNC. Mechanisms of reactions in leprosy. Int J Lepr, 1971; 39: 417-28.

${ }^{3}$ Gelber RH, Epstein V, Fasal P, Drutz DJ. Erythema nodosum leprosum: An immune complex disease. Int J Lepr, 1973; 41: 553-4.

${ }^{4}$ Bryceson A, Pfaltzgraff R E. Leprosy, 2nd ed., Edinburgh, London and New York: Churchill Livingstone, 1979, p. 69.

${ }^{5}$ Moran CJ, Turk JL, Ryder G, Waters MFR. Demonstration of circulating immune complexes in leprosy by $\mathrm{C}_{\mathrm{lq}}$ precipitation. Int J Lepr, 1973; 41: 553.

${ }^{6}$ Godal T. The role of immune responses to Mycobacterium leprae in host defence and tissue damage in leprosy. In Progress in Immunology II, vol. 4. Brent L, Holborow J (eds), North Holland: Elsevier, 1974, pp. 161-9.

7 Mshana RN. Hypothesis: Erythema nodosum leprosum is precipitated by an imbalance of $\mathrm{T}$ lymphocytes. Lepr Rev, 1982; 53: 1-7.

8 Ridley DS. Histological classification and the immunological spectrum of leprosy. Bull WHO, 1974; 51: 451-65.

9 Ridley DS, Waters MFR. Significance of variations within the lepromatous group. Lepr Rev, 1969; 40: 143-52.

10 Strelkauskas AJ, Wilson BS, Dray S. Inversion of levels of human T and B cells in early pregnancy. Nature, 1975; 258: 331-2.

11 Masson PL, Delire M, Cambiaso CL. Circulating immune complexes in normal human pregnancy. Nature, 1977; 266: 542-3.

12 Levinsky RJ, Stirrat GM, Redman CWG. Immune complexes in pregnancy. Lancet, 1978; ii: 1210-11.

13 Duncan ME, Melsom R, Pearson JMH, Ridley DS. The association of pregnancy and leprosy. I. New cases, relapse of cured patients and deterioration in patients on treatment during pregnancy and lactation-Results of a prospective study of 154 pregnancies in 147 Ethiopian women. Lepr Rev, 1981; 52: 245-62.

14 Yoder L, Naafs B, Harboe M, Bjune G. Antibody activity against Mycobacterium leprae antigen 7 in leprosy: Studies on variation in antibody content throughout the spectrum and on the effect of DDS treatment and relapse in BT leprosy. Lepr Rev, 1979; 50: 113-21.

15 Jopling W H. Treatment of acute phases (reactional states) in lepromatous leprosy. In Leprosy in Theory and Practice, 2nd ed. Cochrane RG, Davey TF (eds), Bristol: Wright, 1964, p. 418.

16 Trân̄ Din̄h Dê, Hoang Ngoc, Minh and Cao Minh, Trung. Contribution à l'étude de l'association lèpre et gravido-puerpéralité. Gyn Obst (Paris), 1964; 63: 649-54.

17 Maurus JN. Hansen's disease in pregnancy. Obstet Gynecol, 1978; 52: 22-5.

18 Ridley DS, Jopling WH. Classification of leprosy according to immunity. A five-group system. Int $J$ Lepr, 1966; 34: 255-73.

${ }^{19}$ Duncan ME, Pearson JMH, Rees RJW. The association of pregnancy and leprosy. II. Pregnancy in dapsone-resistant leprosy. Lepr Rev, 1981; 52: 263-70. 
${ }^{20}$ Pearson JMH, Ross WF. Nerve involvement in leprosy-pathology, differential diagnosis and principles of management. Lepr Rev, 1975; 46: 199-212.

${ }^{21}$ Duncan ME, Pearson JMH. Neuritis in pregnancy and lactation. Int J Lepr, 1982; 50: 31-8.

22 Pearson JMH, Haile GS, Barnetson RStC, Rees RJW. Dapsone-resistant leprosy in Ethiopia. Lepr Rev, 1979; 50: 183-99.

${ }^{23}$ Lawson JB, Stewart DB. Obstetrics and Gynaecology in the Tropics. London: Edward Arnold, 1967, pp. 47-9.

24 Jopling WH. Handbook of Leprosy, 2nd ed. London: William Heinemann Medical Books Ltd., 1978, pp. 71, 93.

${ }^{25}$ Stirrat GM. The immunological system. In Clinical Physiology in Obstetrics. Hytten F, Chamberlain G (eds), Oxford, London and Edinburgh: Blackwell Scientific Publications, 1980, pp. 101-44.

${ }^{26}$ Duncan ME, Pearson JMH, Ridley DS, Melsom R, Bjune G. Pregnancy and Leprosy: The consequences of alterations of cell-mediated and humoral immunity during pregnancy and lactation. Int J Lepr, 1982; 50: 425-35.

27 Barnetson RStC, Bjune G, Pearson JMH, Kronvall G. Antigenic heterogeneity in patients with reactions in borderline leprosy. $\mathrm{Br}$ Med J, 1975; iv: 435-7.

28 Stenger EG, Aeppli L, Peheim E, Thomann PE. Toxicology of the antileprotic agent 3-(p-chloroanilino)-10-( $p$-chlorophenyl)-2, 10-dihydro-2-(isopropylimino)-phenazine (G 30, 320) Acute and subchronic toxicity, reproduction toxicology. Arzneim.-Forsch.-Drug Res, 1970; 20: 794-9.

${ }^{29}$ Duncan ME, Oakey RE. Reduced estrogen excretion due to clofazimine? Int J Lepr, 1983; 51: 112-13. 